\section{Category}

Organo- and

Biocatalysis

\section{Key words}

frustrated Lewis pairs

allenes

metal-free

hydrogenation

B. InÉS, D. PAlomas, S. holle, S. STEInberG, J. A. NiCASio, M. AlCARAZO* (MAXPLANCK-INSTITUT FÜR KOHLENFORSCHUNG, MÜLHEIM AN DER RUHR, GERMANY) Metal-Free Hydrogenation of Electron-Poor Allenes and Alkenes

Angew. Chem. Int. Ed. 2012, 51, 12367-12369.

\title{
Frustrated Lewis Pairs for Catalytic Hydrogenation of Allenes and Alkenes
}
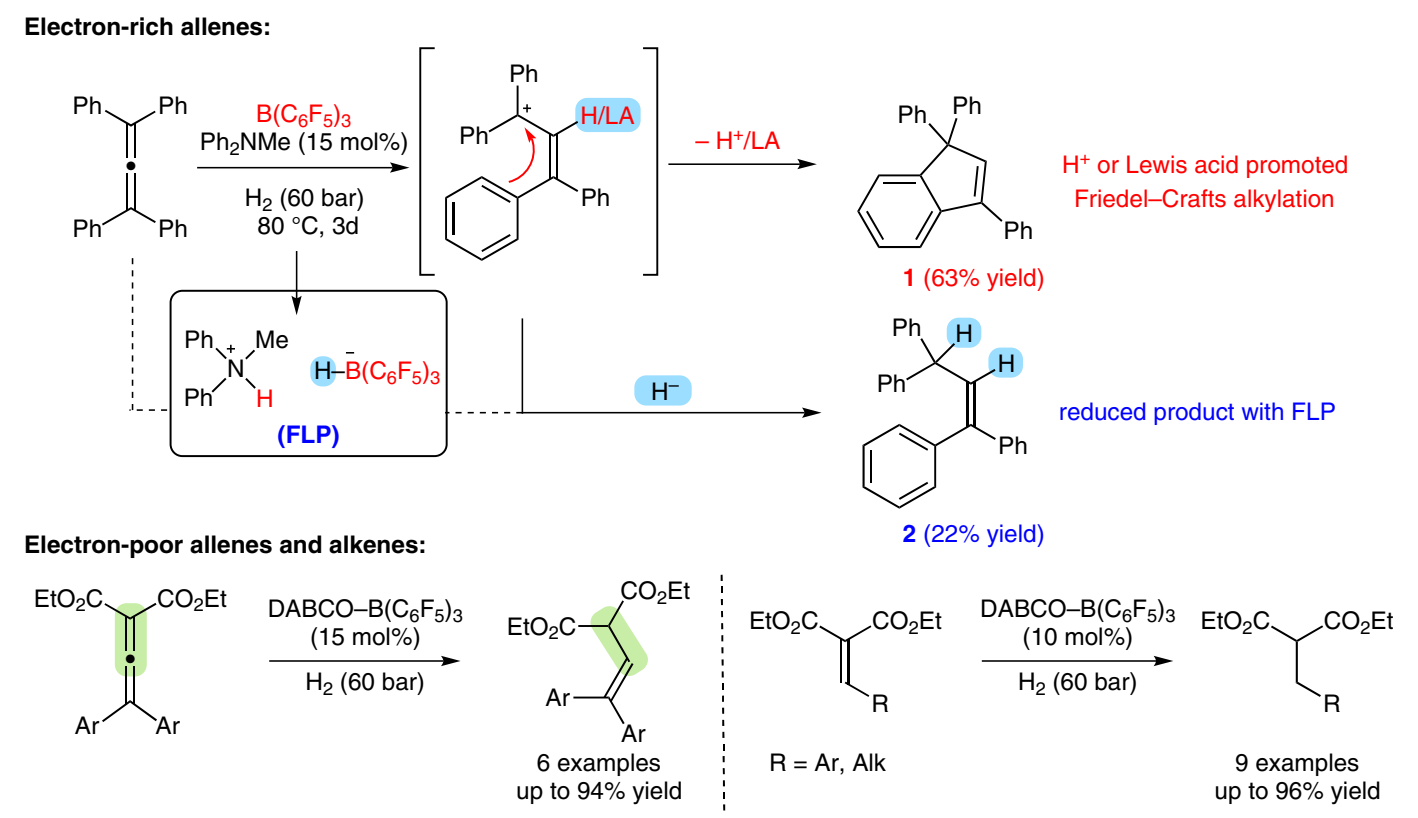

Mechanistic studies:<smiles>CCOC(=O)C(Cc1ccccc1)C(=O)OCC</smiles>

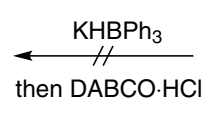

$\mathrm{EtO}_{2} \mathrm{C} \mathrm{Ph}_{\mathrm{Ph}}^{\mathrm{CO}_{2} \mathrm{Et}}$
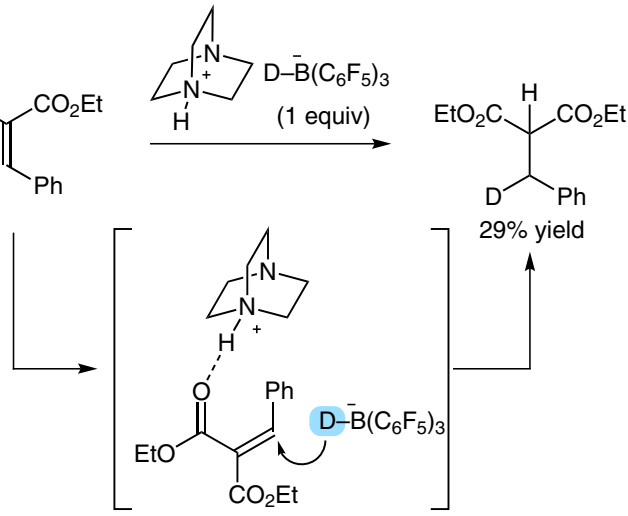

Significance: The Alcarazo group reports a frustrated Lewis pair (FLP)-catalyzed hydrogenation reaction of electron-poor allenes and alkenes. The reduced products were obtained with good to excellent yield and high chemoselectivity by employing $\mathrm{DABCO}-\mathrm{B}\left(\mathrm{C}_{6} \mathrm{~F}_{5}\right)_{3}$ as a catalyst pair (10-15 mol\%).

SYNFACTS Contributors: Benjamin List, Ji-Woong Lee Synfacts 2013, 9(1), 0098 Published online: 17.12.2012 DOI: 10.1055/s-0032-1317905; Reg-No.: B11812SF
Comment: To overcome the inherent reactivity of electron-rich allenes to cyclize to Friedel-Crafts products 1 in the presence Brønsted acids and/or Lewis acids, the authors employ electron-poor substrates to facilitate FLP-catalyzed hydrogenation to the desired product $\mathbf{2}$. According to the mechanistic studies, [DABCO-H] ${ }^{+}$might act as a hydrogen-bond donor to activate the substrate. The hydride from the borohydride is transferred via 1,4-addition. 